\section{Guiding the South Pole Traverse with ASTER imagery}

On 9 December 2004, one of us (R.B.) received a phone call requesting assistance in identifying crevasses in Antarctica. The US South Pole Traverse (SPT) party heading from McMurdo Station $\left(77.90^{\circ} \mathrm{S}, 166.65^{\circ} \mathrm{E}\right)$ to South Pole Station via Leverett Glacier in the Transantarctic Mountains had stopped due to the discovery of numerous crevasses along their planned route. These crevasses had been detected by ground-based ice-sounding radar moving ahead of the heavy traverse vehicles. Investigation of numerous alternative routes also identified many crevasses.

A quick assessment was required, forcing us to limit our investigation of the region between the field party and the mouth of Leverett Glacier to satellite remote sensing imagery already on hand. Two types were examined. The first was the RADARSAT mosaic produced from synthetic aperture radar (SAR) collected over the entire Antarctic continent in 1997 (Jezek and others, 2002). The highest-resolution data available are those of the $25 \mathrm{~m}$ mosaic distributed by the Alaska SAR Facility. The second image source used was $15 \mathrm{~m}$ multispectral optical imagery from the Advanced Spaceborne Thermal Emission and Reflection Radiometer (ASTER).

To our surprise, the RADARSAT imagery failed to show many crevasses that ASTER showed clearly. Two examples are shown for comparison. Crevasse orientation can affect the backscatter signal that a SAR detects, making crevasses aligned with the SAR look direction nearly invisible. This does not explain the poor performance of RADARSAT in our case because the crevasses have various orientations. Some resampling of the SAR data is required to create the RADARSAT mosaic, but as time was pressing, we did not examine the original swath data.

The crevasses visible in the cloud-free ASTER images but not visible in the RADARSAT imagery are of various types. At the margins of a slow-moving area $\left(84.91^{\circ} \mathrm{S}, 157.30^{\circ} \mathrm{W}\right)$ near the bend made by Scott Glacier as it enters the Ross Ice Shelf, are arcuate sets of crevasses on either side formed by shear between the slow-moving ice and Scott Glacier on the south side and Mercer Ice Stream/Reedy Glacier on the north side (Fig. 1). The upstream portion of the north set is visible in the RADARSAT image, but the continuation of these crevasses downstream is not. Even farther downstream on the ice shelf, in the ice that once flowed in Scott Glacier, there are many series of crevasses that cannot be seen in the RADARSAT mosaic (Fig. 2). These are up to $30 \mathrm{~m}$ across (i.e. generally 1-2 pixels wide) and many are $>1 \mathrm{~km}$ long.

We had two ASTER images (each $60 \mathrm{~km} \times 60 \mathrm{~km}$ ) of the area yet to be crossed by the traverse party and were able to quickly order a third scene that included the current position of the field party. These three images covered the next $80 \mathrm{~km}$ of the traverse and came within a few kilometers of the mouth of Leverett Glacier. We defined what we believed to be a crevasse-free route by specifying the coordinates of seven waypoints. Geographic registration was accomplished by ingesting the level 1B ASTER data into ENVI image analysis software.

We are happy to report that by following our new route, the field party was able to travel the $80 \mathrm{~km}$ to the end of our ASTER coverage in just 2 days and encountered no crevasses along the way.

Our experience calls attention to the potential danger of assuming the $25 \mathrm{~m}$ resolution of the RADARSAT mosaic is sufficient to identify all crevassed areas of the ice sheet. This is particularly important for assessing the safety of surface traverse routes.

\section{ACKNOWLEDGEMENT}

We wish to thank G. Hamilton who ordered the additional ASTER imagery.

Code 914, Robert BINDSCHADLER

NASA Goddard Space Flight Center, Greenbelt, Maryland 20771,

USA

$S A I C$,

Patricia VORNBERGER

4600 Powdermill Road, Suite 400

Beltsville, Maryland 20705-2675,

USA

21 March 2005
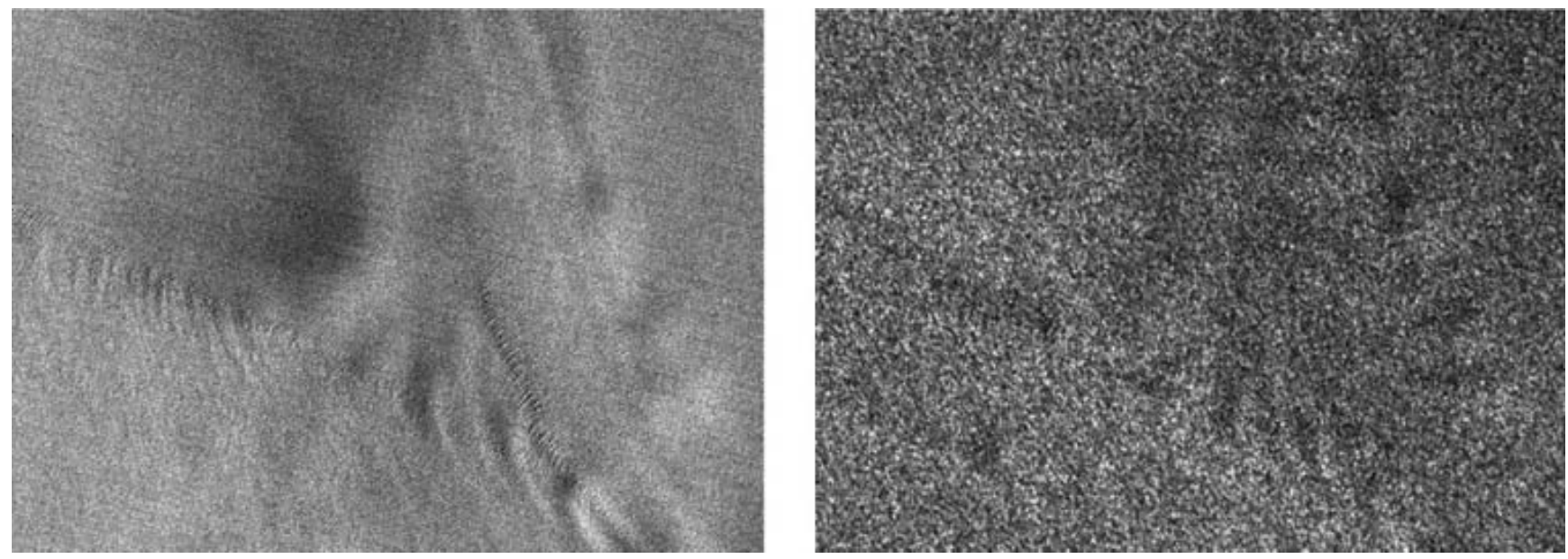

Fig. 1. Comparison of ASTER (left) and RADARSAT (right) imagery in the confluence area of Scott Glacier and Mercer Ice Stream. Image area is $13.5 \mathrm{~km} \times 9.9 \mathrm{~km}$. North is roughly toward the bottom of the image and ice flow is generally to the right. Shear crevasses define the presence of a triangular-shaped area of slower flow in the center of each image. 

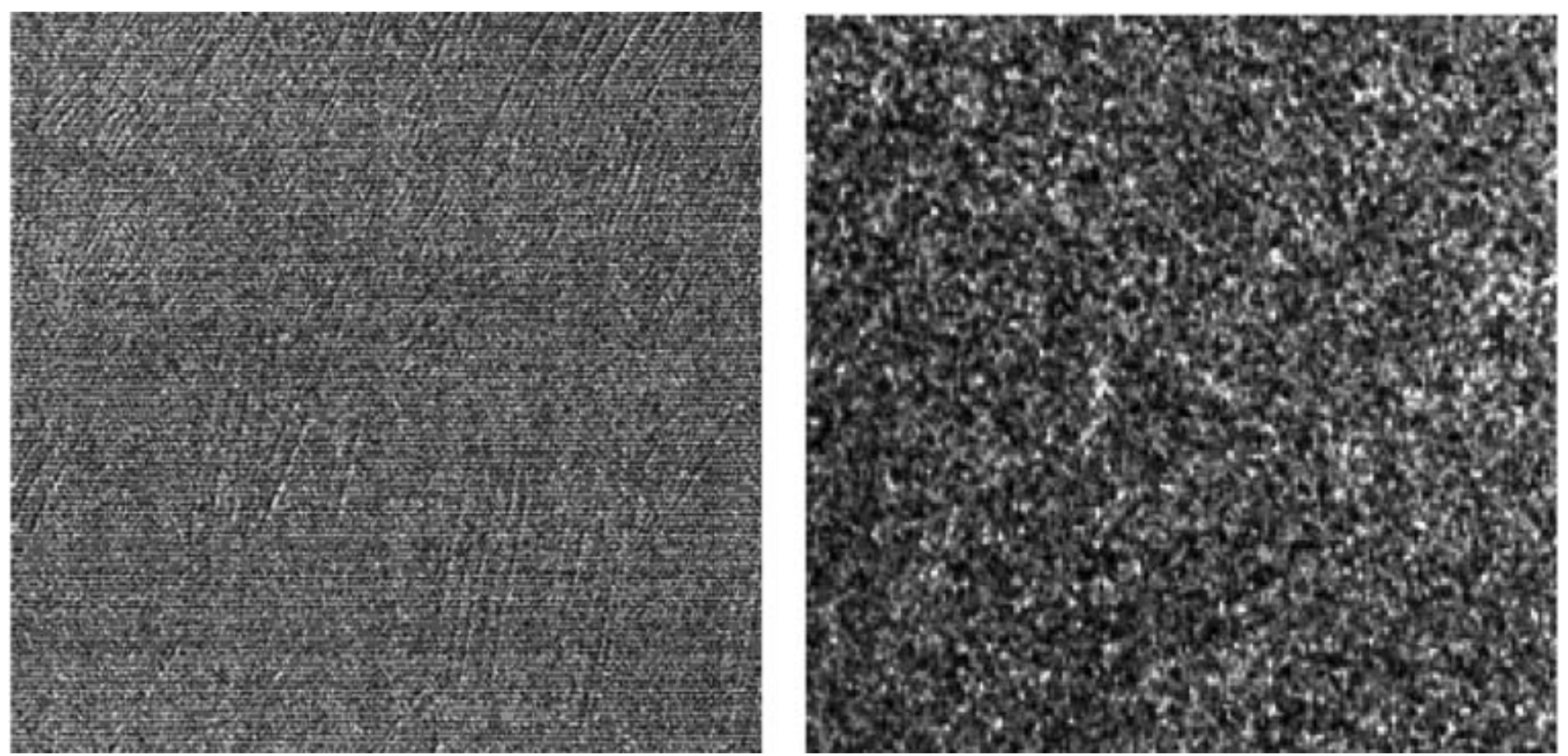

Fig. 2. Comparison of ASTER (left) and RADARSAT (right) imagery centered on the location of the halted field party $\left(84.618^{\circ} \mathrm{S}, 167.00^{\circ} \mathrm{W}\right)$. Image area is $5 \mathrm{~km} \times 5 \mathrm{~km}$. North is roughly toward the bottom of the image and ice flow is generally to the lower right. Crevasses seen in the ASTER imagery are not defined in the RADARSAT imagery.

\section{REFERENCE}

Jezek, K. and the RAMP Product Team. 2002. RAMP AMM-1 SAR image mosaic of Antarctica. Fairbanks, AK, Alaska SAR Facility, in association with the National Snow and Ice Data Centre, Boulder, CO. Digital media. 